\title{
EL EPISTOLARIO REYES-HENRÍQUEZ UREÑA: UNA TRAYECTORIA GULTURAL
}

La vida de Alfonso Reyes (1889-1959), por un lado tan llena y productiva y por otro demasiado breve y truncada en plena actividad intelectual, se presta a múltiples celebraciones y conmemoraciones. En efecto, tradicionalmente los cien años han servido para la retrospectiva constituyéndose en número lógico para reflexionar y evaluar a una figura y su aportación. Pero el caso de Reyes no encaja en este esquema tradicional. Al contrario, su vida y su obra abarcan más de un continente, una literatura y un género para romper patrones conocidos y enfrentarnos a una personalidad y una mentalidad de extraordinarias dimensiones cuyas innumerables facetas han atraído a los estudiosos desde hace años.

Alfonso Reyes, el erudito y humanista por excelencia, fue también gran amigo y corresponsal de muchos. Educado durante la efervescencia intelectual posrevolucionaria, conoció a escritores y otros profesionales que más tarde integrarían la generación del Ateneo, agrupación que marcó el rumbo intelectual y académico del siglo xx en México. De las muchas amistades surgidas en la Sociedad de Conferencias y el Ateneo de la Juventud, ninguna fue más significativa y duradera que la sostenida por Reyes con Pedro Henríquez Ureña. El humanista dominicano, la única figura que podemos equiparar con el intelectual mexicano por sus parecidas cualidades y capacidades, desempeñó un papel inestimable en el desarrollo intelectual y académico de su amigo. Los dos, espíritus afines en muchos sentidos, se inspiraron y alentaron mutuamente a lo largo de sus peripatéticas carreras.

La relación Reyes-Henríquez Ureña es bien conocida y ha sido comentada y estudiada desde hace mucho tiempo. Los que participaron en la renovación intelectual de principios del siglo en México reconocieron la fuerza motriz que ejerció el dominicano Henríquez Ureña sobre sus colegas mexicanos. Reyes, el benja- 
mín del grupo, comprendió el extraordinario talento de su colega y siguió el camino trazado por éste. Afortunadamente, gran parte del epistolario entre Reyes y Henríquez Ureña se ha conservado para proporcionarnos en fuentes originales un rico caudal de datos donde se documenta esa relación personal e intelectual ${ }^{1}$. Este conjunto de escritos, probablemente no destinados al examen general, nos permiten apreciar otra faceta de Alfonso Reyes a la vez que escudriñar un aspecto complementario de su obra conocida. Vale notar que la desigual pero extensa correspondencia no es completa. Hay años en que se escribieron más y otros menos; se han conservado más cartas de ciertas épocas que de otras; sin duda alguna hay ciertas faltas. No obstante, el mero hecho de que haya una colección de cartas que abarca casi cuarenta años de amistad entre los primeros y más prolíficos humanistas hispanoamericanos de este siglo es por sí solo asombroso. Inmediatamente nos preguntamos cómo fue posible que dos personas tan ocupadas con sus propios estudios e investigaciones y, en el caso de Alfonso Reyes, con el problema diario de ganarse la vida durante su estada en Europa, dispusieran de tanto tiempo para escribirse. No podríamos responder adecuadamente a esta pregunta a menos que suscribamos la idea de que una fuerza casi sobrenatural los impulsaba a mantener este intercambio epistolar. Estas cartas, ricas en su variedad de temas, se pueden leer desde diversas perspectivas. A través de ellas podemos seguir la carrera peripatética de los dos escritores; o, si así lo preferimos, el desarrollo de sus investigaciones e intereses; o bien sus contactos con los más notables escritores e intelectuales de ambos lados del Atlántico. En fin, tal correspondencia ofrece múltiples caminos de asedio, todos los cuales rendirían valiosos frutos para la comprensión del ambien-

${ }^{1}$ Consulté y estudié el epistolario primero en la Casa-Museo Alfonso Reyes (Capilla Alfonsina). Quiero dejar constancia de mi agradecimiento a la Sra. Alicia Reyes por sus múltiples cortesías y por haberme permitido examinar las carpetas. Luego en la República Dominicana se publicaron tres tomos de la correspondencia (1906-1946), que el Prof. Juan Jacobo Lara, editor y compilador de estos volúmenes, tuvo la gentileza de enviarme (PEDro HeNRíQUez Ureña y Alfonso Reyes, Epistolario intimo, Universidad Nacional Pedro Henríquez Ureña, Santo Domingo, 1981). Cinco años después un tomo de la correspondencia, cuidadosamente editado y comentado por el Dr. José Luis Martínez, fue publicado en México: Alfonso Reyes/Pedro HenríQuez Ureña, Correspondencia 1907-1914, FCE, México, 1986. Cito por la edición del FCE hasta donde sea posible y por la edición de la Universidad Nacional Pedro Henríquez Ureña (UNPHU) del año 1914 en adelante. Indico en todos los casos la fecha, la edición, el volumen y la página correspondientes. 
te cultural hispánico de la primera mitad de este siglo.

Vale recordar cómo se conocieron Pedro Henríquez Ureña y Alfonso Reyes y cómo lograron mantener su amistad por cuatro andariegas décadas. Esta historia es por sí sola interesante, pero tanto más significativa si medimos los resultados intelectuales. Pedro Henríquez Ureña llegó a México en 1906 e inmediatamente se vinculó a diversos grupos literarios; precisamente conoció a Alfonso Reyes en la redacción de la revista Savia Moderna. De este encuentro recuerda el mexicano:

... se me figuró un ser aparte, y así lo era. Su privilegiada memoria para los versos - cosa tan de mi gusto y que siempre me ha parecido la prenda de la verdadera educación literaria- fue en él lo que desde luego me atrajo. Poco a poco sentí su gravitación imperiosa, y al fin me le acerqué de por vida. Algo mayor que yo, era mi hermano y a la vez mi maestro. La verdad es que los dos nos íbamos formando juntos, él siempre unos pasos adelante 2 .

El juicio de Alfonso Reyes muestra la curiosa relación entre ambos humanistas: el uno discípulo y el otro maestro, amigos fraternales en un vínculo de delicado equilibrio. Esta amistad iniciada en 1906 es quizás única en la historia de las letras hispanoamericanas. Como fue un intercambio querido y apreciado por los dos sería inexacto decir que el uno dominaba al otro. Al contrario, Reyes buscaba y pedía los consejos y opiniones de Henríquez Ureña y cuando le llegaban aun a través de océanos y continentes, los aceptaba y los hacía suyos. De esta manera el dominicano le proporcionó el impulso necesario para que su innato talento floreciera; en otras palabras, Pedro Henríquez Ureña fue el agente catalizador que estimuló y orientó a Alfonso Reyes. Aunque la voz del primero se escuchaba con mayor autoridad, este intercambio se nos revela como armonioso conjunto cuya constante es una sana interdependencia intelectual.

Del verdadero respeto y cariño entre el dominicano y el mexicano hay indicaciones en cada una de las cartas. En los días difíciles de 1911, Reyes, por entonces en México, le escribe a Henríquez Ureña en Cuba: "De la ciudad nada tengo que contarte: nada sucede aquí en tu ausencia. Yo nunca vi las cosas de Méxi-

2 Alfonso Reyes, “Encuentros con Pedro Henríquez Ureña', RevIb, 21 (1956), p. 56. Este número dedicado a Pedro Henríquez Ureña ofrece importantes estudios sobre su vida y obra. 
co por mis propios ajos, sino por los tuyos, así es que ahora no distingo nada"3. Y de París en 1913 le dice:

Si te hablo de mi soledad es porque, como tú comprenderás, no es posible que os sustituya. Los franceses no son gente para recibir en su intimidad a ningún extranjero. Y las gentes de habla española que hay en París, ni conocerlas deseo ${ }^{4}$.

De esta necesidad de comunicarse con su amigo hay infinitos ejemplos:

Otra vez seré más explícito. Te quisiera decir muchas cosas, ya que por ahora no puedo hablarte; todas las noches te sueño, y me sueño conversando contigo largamente. Si tú no sueñas lo mismo, no mereces que te escriba ${ }^{5}$.

Henríquez Ureña, receptivo a los sentimientos de su amigo y a la vez resignado a las separaciones inevitables, anima a Reyes con las siguientes palabras:

$\mathrm{Al}$ entregarme tu carta tuve la misma impresión que cuando recibo cartas de mi padre: la de que sólo me habías de hablar de cosas tristes. [ ...] Yo concibo la correspondencia como placer, mucho más que como desahogo. Haz, pues, un esfuerzo, y nunca escribas sino cartas amenas, que se puedan enseñar a los amigos. [ . . . ] Porque lo más grave de una carta triste es la imagen que da del estado de ánimo en que vive el que la escribió. En cambio, aunque el escribir cartas amenas te cueste esfuerzo, el esfuerzo mismo influirá en que tengas una o dos horas alegres después de escribir. Prueba ${ }^{6}$.

De Madrid, anticipando una visita de tres meses de su amigo dominicano, es Reyes quien lo alienta diciéndole que todos los esperan y si a él le mejoran el sueldo habrá para los dos, "pues estamos acostumbrados a compartir la vida"7. Aun años más tarde, cuando su situación económica era menos precaria y su reputación de escritor y crítico bien establecida, Reyes sigue anhelando la comunicación con Henríquez Ureña: "Necesito cartas largas, orientadoras, explícitas, burguesas, honradotas, al pan pan

${ }^{3} 6$ de mayo de 1911, FCE, p. 169.

428 de septiembre de 1913, FCE, p. 196.

57 de mayo de 1914, FCE, pp. 307-308.

630 de mayo de 1914, FCE, pp. 335-336.

718 de octubre de 1916, UNPHU, t. 3, p. 16. 
y al vino vino. De otro modo me pierdo" 8 . A los dos años desde París, agobiado por el trabajo y los muchos compromisos, le dice: "Ponme unas letras: nada te cuesta decirme alguna cosa agradable, y a mí me hará mucho bien. No me dejes solo en este valle de lágrimas" "9. Y el año siguiente, en un tono íntimo, alude a los veinte años que se han conocido y expresa de nuevo lo mucho que lo extraña y lo importante que son las comunicaciones y los consejos que le llegan de su amigo:

Te he deseado tanto, te he echado tanto de menos. Desgraciadamente (¡oh sueños de nuestros 20 años!) las palabras no sirven bien para entenderse, sino con los que hablan nuestro mismo lenguaje en el otro sentido, más profundo, de la palabra. Y me pregunto cuántos hay por el mundo, además de Pedro, a quienes pueda yo hablar de ciertas cosas, de ciertas dudas estéticas, de ciertas crisis intelectuales ${ }^{10}$.

De regreso en México en 1939, ya tranquilo y seguro de sí mismo y de su futuro, se nota que, por costumbre o quizá por sentimentalismo, todavía pide la aprobación de Pedro Henríquez Ureña. Le explica detalladamente por qué no aceptó una cátedra en la Universidad de Tejas, su decisión de aceptar la Presidencia del Patronato de la Casa de España y su próxima mudanza a una nueva casa. Sin embargo, a pesar de los años y de las muchas experiencias vividas alejado de su amigo, le dice: "Me haría mucho bien recibir de ti una palabra de aprobación, por sobria que sea"11.

Tanto Alfonso Reyes como Pedro Henríquez Ureña compartieron un amor por la cultura en el sentido más amplio de la palabra; este amor los lleva a buscar, estudiar, leer y discutir constantemente temas literarios, filosóficos y artísticos. Su insaciable sed de beber de todas las fuentes culturales es quizás lo que más llama la atención a través de la correspondencia. No hay ni carta ni tarjeta postal que no tenga pregunta, respuesta u opinión acerca de un tema cultural o un escritor o artista. De modo que el epistolario se podría leer como una historia personal de la creación literaria y artística del momento y también de la crítica que se estaba haciendo sobre ella y sobre generaciones anteriores. Las

821 de mayo de 1923 , UNPHU, t. 3, p. 239.

928 de marzo de 1925, UNPHU, t. 3, p. 283.

${ }^{10} 19$ de enero de 1926, UNPHU, t. 3, p. 311.

1122 de marzo de 1939, UNPHU, t. 3, p. 462. 
cartas muestran un tono de seriedad en cuanto a sus investigaciones que sería desusado en el trato personal y más si tomamos en cuenta la vía de comunicación. La nota de seriedad evidente tanto en la obra de Alfonso Reyes como en la de Pedro Henríquez Ureña es indudablemente el rasgo más sobresaliente de la correspondencia que se ha conservado. Fue Martín Luis Guzmán quien en su descripción del Ateneo de la Juventud (1920) señaló esa cualidad como la más característica del grupo y la que unió a sus socios a pesar de diferencias de profesión y formación:

Caracterízase este grupo por una cualidad de valor inicial indiscutible, si bien de mérito muy diverso y abierto a todas las apreciaciones en cuanto a la realización personal: la seriedad. La seriedad en el trabajo y en la obra; la creencia de que las cosas deben saberse y aprenderse de primera mano, hasta donde sea posible; la convicción de que así la actividad de pensar como la de expresar el pensamiento exigen una técnica previa, por lo común laboriosa, difícil de adquirir y dominar, absorbente, y sin la cual ningún producto de la inteligencia es duradero; el convencimiento de que ni el arte, ni las letras son mero pasatiempo o noble escapatoria contra los aspectos diarios de la vida, sino una profesión como cualquiera otra, a la que es ley integrarse del todo, si hemos de trabajar en ella decentemente, o no entregarse en lo mínimo ${ }^{12}$.

Este Martín Luis Guzmán es el mismo que muchos años antes en la preparación de una serie de conferencias llamó la atención a Henríquez Ureña y del que comentó a Alfonso Reyes:

Me han encomendado que tantee al único joven que aparece por el horizonte, id est, Martín Guzmán; lo haré, a ver si es posible que en un mes y con una influencia ordenada haga algo presentable. [...] En estos días se me ha acercado dos veces, y veo que en realidad es inteligente y tiene verdadera eagerness por ascender a las cosas intelectuales ${ }^{13}$.

Ese joven hablaría años después de "las dotes extraordinarias" de Alfonso Reyes y de la "voz orientadora infatigable" de Pedro Henríquez Ureña ${ }^{14}$.

La correspondencia entre Reyes y Henríquez Ureña ilustra mejor que cualquier tratado o manual en qué consisten la erudi-

12 Martín Luis Guzmán, "Alfonso Reyes y las letras mexicanas", $A$ orillas del Hudson, Botas, México, 1920, pp. 48-49.

134 de febrero de 1908, FCE, pp. 83-84.

${ }^{14}$ GuZMán, op. cit., pp. 47-52. 
ción y la crítica. Tanto el uno como el otro se daban cuenta de la seriedad de lo que estaban haciendo y por eso se consultaban constantemente para verificar algún dato, confirmar una nota bibliográfica, aclarar un punto dudoso, perfeccionar el estilo o el lenguaje. Su obra fue un constante cuestionamiento, un esfuerzo de superación, una necesidad de leer otras literaturas en su lengua original y dominar sus matices. $\mathrm{Y}$ a pesar de las distancias, las frecuentes mudanzas y las difíciles vías de comunicación de esos años, cada uno servía de caja de resonancia para el otro y no para la adulación mutua. A veces eran severos en sus comentarios, pero siempre positivos en su deseo de ayudar al colega a mejorarse y perfeccionarse. De este intercambio encontramos innumerables ejemplos en la correspondencia, ejemplos que se extienden de una simple pregunta a páginas enteras que trazan línea por línea dudas, preguntas y correcciones. Para todos los que aspiran a ser escritores y críticos, el epistolario Reyes-Henríquez Ureña proporciona una lección maestra.

Entre los muchos temas que llaman la atención en el epistolario sobresale el intercambio cultural del mundo hispánico en ambas orillas del Atlántico. Las cartas nos dan clara constancia de que la obra de escritores y críticos hispanoamericanos ya era conocida en Europa en la segunda década de este siglo a pesar de las limitaciones de los medios de comunicación y transporte. En esos años y los subsecuentes muchos artistas y escritores hispanoamericanos se encontraban en Francia y España, donde convivieron con colegas europeos. Se desarrolló entonces un interés mucho más amplio en la crítica que el limitado a la literatura nacional del investigador. Dos ejemplos que ilustran este fenómeno son precisamente Alfonso Reyes y Pedro Henríquez Ureña, quienes se dedicaron tanto a la literatura española como a la hispanoamericana porque veían las letras hispánicas como una unidad intrínseca. Sin embargo, Alfonso Reyes, quien desde sus primeros años en Europa se abría paso entre los intelectuales, quedó muy impresionado al darse cuenta de que ya por los años de 1914 y 1915 su labor crítica y la de Henríquez Ureña eran conocidas allí. En efecto, al llegar Reyes a España visitó a Azorín y entre otros temas hablaron de Henríquez Ureña. Le comenta Reyes en una carta que "[Azorín] te ha leído en La Revista de América: te considera muy superior a la América esa de Francisco García Calderón, etc., etc."'15. Y de Madrid le escribe:

1519 de septiembre de 1914, FGE, p. 477. 
Yo aquí voy abriéndome paso. Literariamente, muy bien. Nos conocen a ti y a mí, y nos siguen. Díez-Canedo muy culto e inteligente conoce a Manuel José Othón: conoce a Nosotros. Te admiran. Me dijo: no sólo los seguíamos, sino los deseábamos aquí ${ }^{16}$.

Cuando Reyes se unió al Ateneo de Madrid y al Centro de Estudios Históricos le escribió a Henríquez Ureña en Washington: "Todo el mundo me pregunta aquí por ti: tienes una sólida y envidiable reputación" 17 . Un mes más tarde en una comunicación rápida sobre sus actividades en el Centro de Estudios Históricos, donde conoció entre otros a Ramón Menéndez Pidal, le dice a su colega dominicano: "Esta gente es nuestro grupo. No estábamos solos en México. En Perú, en Cuba, en Mạdrid, existíamos también"18. Seguramente se refiere a las investigaciones y actos culturales que tuvieron su origen en el Ateneo de la Juventud, actividades que se complementaban en otros países. Otra vez, en una carta de 1915 que versa sobre distintos temas, le habla a Henríquez Ureña del hecho de que los dos sean conocidos en los círculos literarios de Madrid. Con el paso de los años, los viajes frecuentes y los distintos puestos ocupados, ambos dejaron su fama bien establecida en Europa y América. Sin embargo, lo que aquí nos llama la atención es el temprano reconocimiento de la capacidad intelectual de dos hispanoamericanos en los círculos europeos, frecuentemente cerrados a otras influencias.

Además de enfocar el epistolario por el caudal de material que proporciona, podemos apreciar a los dos corresponsales como seres vivos que compartían comunes rasgos humanos. Hay detalles sobre el matrimonio, los hijos, la familia; hay comentarios sobre colegas y políticos; hay crítica literaria de toda especie. Los sentimientos personales oscilan entre el desaliento, la tristeza, la felicidad y la euforia. Y quizá lo que hace que la lectura de un epistolario tan rico y abundante sea placentera es el humor que caracteriza el estilo tanto de Reyes como de Henríquez Ureña. En los momentos más difíciles saben introducir una nota cómica, un juego de palabras, una expresión en inglés, francés o latín, algún detalle que revela el nivel íntimo de su relación. En cuanto a Henríquez Ureña es probable que su tono mexicano, tan palpable en este epistolario, le sirviera a Alfonso Reyes de fuente de aproxi-

1610 de octubre de 1914, UNPHU, t. 2, p. 72.

1727 de noviembre de 1914, UNPHU, t. 2, p. 95.

1824 de diciembre de 1914, UNPHU, t. 2, p. 115. 
mación al México ausente. El conocido mexicanismo de Pedro Henríquez Ureña, un aspecto marginal pero de sumo interés en esta correspondencia, merece atención ${ }^{19}$. De este sentimiento impresiona la compenetración con todo lo mexicano de parte del dominicano, a la vez que su manera mexicana de pensar y de expresarse. Por su identificación completa con el ambiente y también por los sentimientos encontrados hacia México - la pasión por la patria adoptiva que hace suya - a veces parece más hijo de la patria de Juárez que Alfonso Reyes. Efectivamente, como el mexicano que ama ferozmente lo suyo y a la vez detesta los problemas ocasionados por la burocracia gubernamental, se queja Henríquez Ureña:

Es una desgracia tener que trabajar en cosas serias en este país. Necesito de las bibliotecas, y la Nacional está cerrada por reparaciones, la de Jurisprudencia se cierra a las 12 y a las 6 , y la de Preparatoria tiene algunos libros, pero los italianos que tiene el catálogo no se sabe dónde están y los poetas españoles ocurre que están en un estante cuya puerta está atascada, y no hay modo de sacar los libros, porque desde hace dos semanas no se les ocurre llamar al carpintero ${ }^{20}$.

La autocrítica también característica del mexicano se nota en el humanista caribeño cuando habla de sus colegas que no le han escrito a Cuba: "Supongo que a los demás es imposible hacerlos escribir. Los mexicanos son gentes que no viajan y, por lo tanto, no saben escribir cartas"'21. Al escribirle a Reyes a París de sus planes de viajar a Europa, insiste en querer vivir fuera del ambiente hispanoamericano y mexicano: "Ya sabes que en Europa no quiero tratarme con más hispano-americanos que los indispensables. Y menos quiero el ambiente de chismoteo político mexicano" 22 . Como todo buen mexicano que profesa un odio a la política a pesar de que la vida del país está tan ligada a ella, dice Henríquez Ureña al contarle a Reyes de una invitación de José Vasconcelos a unirse a la Escuela Nacional Preparatoria:

19 Para mayor información sobre la actuación de Pedro Henríquez Urena en México, véanse Alfredo A. Roggiano, Pedro Henríquez Ureña en México, UNAM, México (en prensa); y Gabriella de Beer, "Pedro Henríquez Ureña en la vida intelectual mexicana", CuA, 1977, núm. 215, pp. 124-131.

202 de febrero de 1909 , FCE, p. 134

214 de mayo de 1911, FCE, p. 167.

${ }^{22} 17$ de junio de 1914, FCE, p. 363. 
Mi primera impresión fue: no. Mi segunda: no. Mi tercera: no. Pero pregunté, y vi que los demás no hallaban tan mala la proposición; lo cual, por supuesto, no me hizo cambiar de actitud. He llegado a pensar que no debemos aceptar ninguna situación sobre la cual pueda caer la menor sombra de duda, aunque interiormente tengamos absoluta pureza de intención. Mucho he tenido yo que pagar culpas de ser amigo personal de políticos, y no quiero que se me siga clasificando políticamente, pues que detesto la politica ${ }^{23}$.

Reyes a lo largo de su correspondencia revela el mismo sentimiento de amor y odio por su país y un parecido recelo de la política. En el caso del mexicano es fácil de comprender por la actuación política de su padre, el general Bernardo Reyes, y el largo destierro de la familia. Reyes siempre está pendiente de todo lo que está pasando en México y de las actividades de sus amigos y colegas. Por un lado atribuye sus problemas a México y por otro anhela regresar a la patria cuando el momento sea oportuno. Sus sentimientos reflejan una comprensible combinación de nostalgia, ira, orgullo, amor y tristeza. En una época de muchas labores para seguir adelante en Madrid, se ve tentado a aceptar un trabajo menor que le ofrece Luis G. Urbina. Pero al pensarlo se siente algo ofendido y le consulta a su amigo Henríquez Ureña, expresándole todas sus reservas:

Hazte cargo de mi situación con respecto al desterrado para quien no hay perdón, por ahora. Piensa si me conviene aceptar esa situación subordinada y ese sueldecito de mi tierra, para que crean allá que acepto la caridad que se me hace; o si debo poner claras las cosas y advertir que yo de mi país sólo puedo aceptar un alto honor y una situación en que yo sea cabeza. No lo digo por Luis, que es tan bueno y bien intencionado, sino por mí mismo. Piénsalo tú con serenidad, y dime tu opinión. Dadas mis condiciones ante mi país, creo que no debo recibir favorcitos, francamente. Si quieren algo de mí, que me lo propongan de allá y me den lo mío, no cualquier cosa. Para aceptar cualquier sueldecito, prefiero los del extranjero. No quiero rebajar mi cotización mexicana ${ }^{24}$.

Queda mucho por decir de la correspondencia Alfonso ReyesPedro Henríquez Ureña. De igual manera que la obra de los dos humanistas sigue siendo una fuente inagotable de estudio e in-

2313 de septiembre de 1914, FCE, pp. 467-468.

${ }^{24} 22$ de septiembre de 1917, UNPHU, t. 3, p. 60. 
vestigación, nos encontramos aquí con un caudal de material que merece mayor atención. Esto no es únicamente porque el epistolario corresponda a dos figuras famosas e importantes; se debe a otros factores, cada uno de los cuales es significativo. Desde el punto de vista histórico las cartas nos proporcionan la oportunidad de estudiar el curso de la crítica literaria en España y América. Los viajes de los dos amigos y los puestos que ocuparon en diferentes países y continentes los pusieron en contacto con los intelectuales más importantes de su época. Por eso la lectura del epistolario nos da una vista casi privada de las actividades culturales de México, Cuba, España y Argentina, entre otros países. Reyes y Henríquez Ureña tuvieron trato personal con los primeros escritores, críticos y artistas de nuestro siglo; a través de sus cartas los vemos como seres vivos y activos y no como personas relegadas a manuales y libros de historia. El epistolario ofrece una gráfica descripción del Ateneo de la Juventud y de la sacudida intelectual de principios de siglo en México. Tal vez de mayor importancia para nosotros es la imagen que las cartas muestran del intercambio cultural en el mundo hispánico en ambas orillas del Atlántico. De igual interés es la posibilidad de seguir el desarrollo intelectual tanto de Reyes como de Henríquez Ureña con base en estas cartas rebosantes de detalles sobre sus lecturas, amistades, trabajos, estudios, visitas a museos, teatros y bibliotecas, etc. Además del desarrollo intelectual de cada uno y el común afán de perfeccionamiento, percibimos claramente una indeleble influencia mutua marcada por el impulso alentador y el predominio del dominicano sobre el mexicano. Si estas cartas les sirvieron a Alfonso Reyes y Pedro Henríquez Ureña de vía de comunicación, de intercambio intelectual y de aliento, también para nosotros hoy día ellas son inestimable fuente de información e inspiración. En suma, hay más que motivos suficientes para celebrar el centenario de Alfonso Reyes. El estudio de su obra y su correspondencia con Pedro Henríquez Ureña nos muestra de nuevo en qué consiste la verdadera erudición y la adquisición y transmisión de la cultura. Ése es el imperecedero legado de Alfonso Reyes que nos pertenece a todos. 